\section{A complex mind}

\author{
II Nobel dimenticato: La vita e la scienza di \\ Camillo Golgi (The Forgotten Nobel: the \\ Life and Science of Camillo Golgi) \\ by Paolo Mazzarello \\ Bollati Bor inghier i: 2006.660 pp. $€ 40$ \\ www.bollatiboringhieri.it
}

\section{Elio Raviola}

I can hardly suppress my irritation when, in reading a paper, I come across the term 'golgi complex' with a lower-case ' $\mathrm{g}$. This is because, as a medical student at the University of Pavia in Italy, I grew up among the epigones of the 'Golgi school', and as an intern there I learned the tricks of Camillo Golgis 'black reaction' for staining neurons directly from A. Pensa, one of his surviving students. However, I was shocked that people in the lab still uncritically believed in the existence of Golgis 'diffuse nervous network', rejected the well-established fact that neurons are cells independent of one another, and ignored the works of Charles Sherrington and Bernard Katz on synapses.

What was it in Golgis personality that commanded such blind faith that his mistakes were carried over to the pupils of his pupils? Why am I still upset that, in the mind of most English-speaking neuroscientists, Golgins name is indelibly associated with his staunch defence of the flawed reticularist theory? Is it simply that a few wrong interpretations should be allowed to taint his reputation despite an otherwise stellar scientific career? More likely, I am also under the spell of Golgi's enigmatic personality. After all, he is the genius who revolutionized neuroanatomy with a method that, for the first time, revealed neurons in their entirety and with the outmost clarity. He was the first to unequivocally describe dendrites and axons, to distinguish interneurons from relay neurons, and to provide descriptions of the cerebellar cortex, olfactory bulb and hippocampus. He was the cytologist who identified the apparatus that bears his name (the only eponym that today defines a major component of the cell). He was the general pathologist who discov-

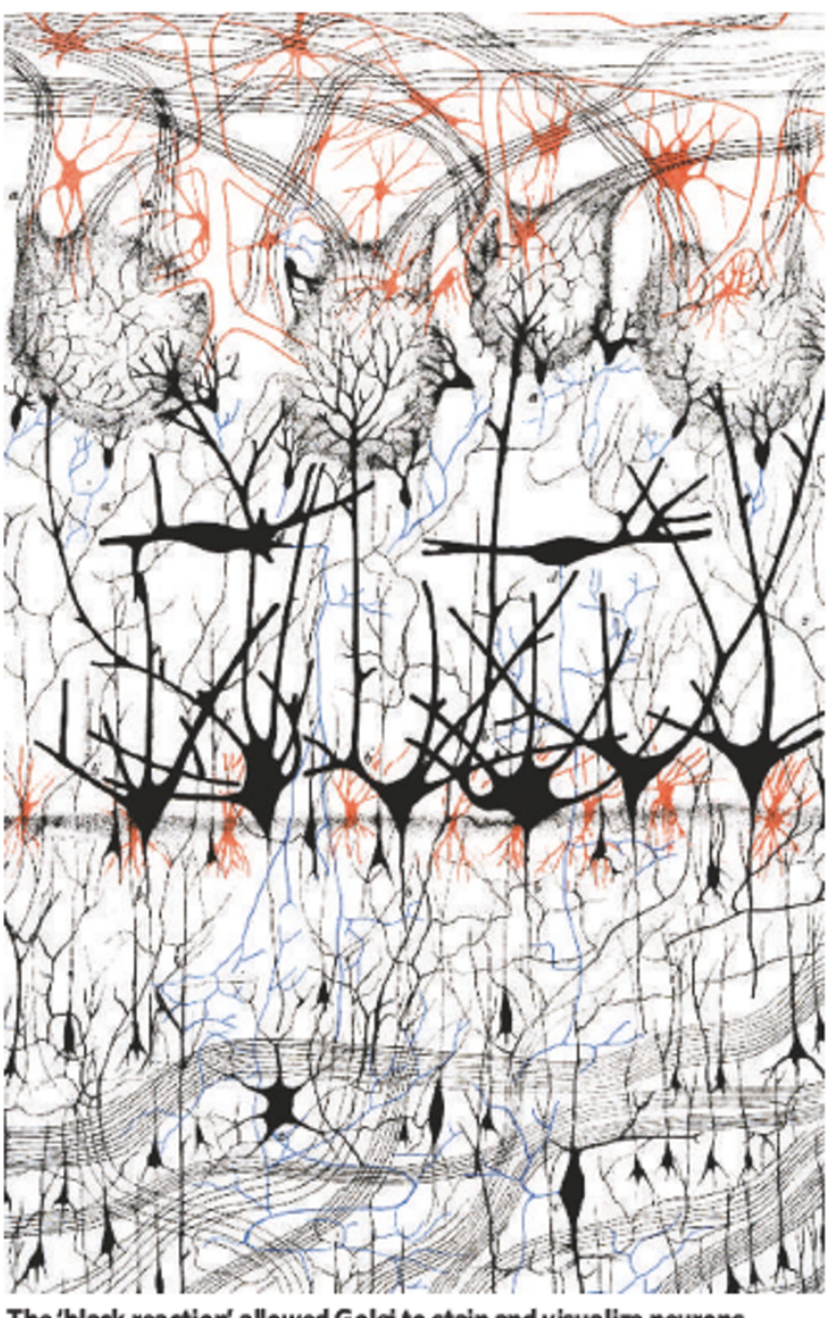

The answers to all these questions, and many more, are contained in Il Nobel dimenticato, a marvellous book by Paolo Mazzarello, historian of medicine at the University of Pavia. Published to mark the centenary of the Nobel prize awarded to Golgi and Ramon y Cajal, the book represents the most complete analysis yet of the life, personality, discoveries and ideas of Golgi. It comes seven years after Mazzarello's first work on Golgi, The Hidden Structure (Oxford University Press, 1999). Mazzarello is clearly partial to his subject, as one might expect of a historian who was a student at the University of Pavia and who still walks every day past the sombre, imposing statue of Golgi in the university's courtyard. Being at Pavia he viciously attacked his competitor's ideas and research style.

Mazzarello provides a thorough psychological portrait of this introverted, shy and intimidating man, who liked to quote the Roman historian Tacitus: "I never regretted being silent, but always regretted having talked." Pensa told me that as an intern in Golgi's laboratory, he was paralysed by the ${ }^{\alpha}$ icy stare of his cerulean eyes". In stark contrast to the ebullient, passionate Cajal, Golgi was an uninspiring speaker who read from his notes, leading many students, including some of the interns at his laboratory, to desert his lectures; he had to threaten them with expulsion to make them sit his classes. Mazzarello deftly discusses why such a skilled microscopist and experimental scientist, a committed positivist who rejected any metaphysics, continued to defend the lost cause of the reticularist theory. However, his prestige, political acumen and careful judgement (his mantra was 'educative caution') helped him become president of the university, a city councillor, a member of the Italian Congress and a prime mover in the cut-throat competitions for departmental chairs in Italian medical faculties.

The book also provides an accurate description of academic life at the University of Pavia, long after the glorious days of Lazzaro Spallanzani, Alessandro Volta and Antonio Scarpa, when it had been second only to Vienna as the seat of learning in the Austro-Hungarian empire. It tells of the political affairs in Pavia, a small, provincial city in northern Italy, which had just become part of a unified, independent kingdom. And it provides a lively account of the interactions among biomedical scientists in Europe in the second half of the nineteenth century, an era of great discoveries, friendships and enmities, violent personal attacks and romantic, rhetorical praise.

I hope Mazzarello's book will be translated into English. Perhaps a better knowledge of Golgi's extraordinary discoveries, and a perusal of Mazzarello's arguments, might persuade the members of the Cajal Club - a society created in 1947 by US neuroanatomists in honour of ${ }^{\prime} \mathrm{el}$ sabio de Madrid - to change its name to the Cajal and Golgi Club. After all, as Mazzarello points out, the discovery ered the pathophysiology of malaria, linking its febrile episodes to the completion of the protozoan's division within the erythrocytes and the release of the resulting merozoites into the bloodstream - he should have received a second Nobel prize for this discovery alone. And these are just a few of a stream of findings, each sufficient to represent a lifetime of achievement for an ordinary scientist. gives him access to Golgi's original slides and allows him to handle his beautiful drawings in the university's museum. Even so, the book contains the most thorough and dispassionate analysis of the controversy between Golgi and Cajal, a convincing exposition of the prevailing zeitgeist at the time of their discoveries, and a justification (or lack thereof) of Golgis behaviour at the Nobel prize ceremony, where of the black reaction came out of the blue, as a total surprise, and so represents an almost unique epistemological event in the history of biomedical science. And without the black reaction, Cajal may not have turned his attention to the nervous system in the first place. Elio Raviola is in the Department of Neurobiology, Harvard Medical School, Boston,

Massachusetts 02115, USA. 